doi:10.1111/j.1365-2052.2008.01713.x

\section{Detection of SNPs in bovine immune-response genes that may mediate resistance to the cattle tick Rhipicephalus (Boophilus) microplus}

\section{A. R. R. Abatepaulo*, A. R. Caetano ${ }^{\dagger}$, C. T. Mendes Jr ${ }^{\ddagger}$, W. A. Carvalho*, B. R. Ferreira* ${ }^{*}$, and I. K. F. de Miranda Santos*, ${ }^{\dagger}$}

* Department of Biochemistry and Immunology, Ribeirão Preto Medical School, Ribeirão Preto, São Paulo, SP, 14049-900, Brazil. ${ }^{\dagger}$ Genetic Resources and Biotechnology Center, Brazilian Enterprise for Agricultural Research, Brasília, DF, 70770-900, Brazil.

${ }^{\ddagger}$ Department of Genetics, Ribeirão Preto Medical School, Ribeirão Preto, São Paulo, SP, 14049-900, Brazil. ' Department of Maternal Nursing and Public Health, Ribeirão Preto School of Nursing, University of São Paulo, Ribeirão Preto, SP, 14049-900, Brazil Accepted for publication 17 January 2008

Source/description: Ticks cause serious losses in animal productivity. Bovine hosts express heritable, contrasting phenotypes when exposed to Rhipicephalus microplus. Bos indicus breeds are significantly more resistant to infestations than Bos taurus breeds. Animals in populations derived from crosses between these groups show varying levels of resistance, ${ }^{1}$ indicating a polygenic basis for the trait. Different breeds also develop qualitatively distinct immune responses against ticks ${ }^{1}$ and their tick-infested skin expresses significantly different levels of mRNA for the immune response genes studied herein. We examined genomic sequences of the genes TGFB1, CXCL1O (also known as IP-10), TNF, IFNG, CCL3 (also known as MIP-1 $\alpha$ ), IGF1 and CCL2 (also known as MCP-1) for the presence of breed-specific SNPs by comparing PCR-amplified genomic sequences from tick-resistant and tick-susceptible bovine breeds.

Methods: Genomic DNA was extracted from animals [Nelore, B. indicus $(n=16)$; Holstein, B. taurus $(n=16)]$ with the PureGene kit (Gentra Systems, Inc.) and $25 \mathrm{ng}$ of DNA from each animal was PCR-amplified with specific primers designed to generate amplicons anchored on two exons and spanning at least one intron (Table S1). The amplicons varied between 900 and $1500 \mathrm{bp}$ in length. PCR fragments were purified with the ExoSapit ${ }^{\mathrm{TM}}$ kit (GE Healthcare) and sequenced (ABI 3100 DNA Analyser). Sequences were processed with PHRED $^{2} /$ PHRAP (http:// www.phrap.org/phredphrapconsed.html) and CONSED $^{3}$ and SNPs were identified with POLYPHRED. Allele frequencies were estimated with GENALEX6. ${ }^{4}$ Given the high levels of linkage disequilibrium between SNPs from the same gene, haplotypes of each individual were reconstructed by means of the EM algorithm ${ }^{5}$ as implemented in the HELIXTREE 6.0.1 program (Golden Helix Inc.). Differences in the distribution of allele and haplotype frequencies between the two breeds were analysed with Fisher's exact test. Adherences of genotypic proportions to expectations under Hardy-Weinberg equilibrium were tested by the complete enumeration method employing GENEPOP 3.4 software. ${ }^{6}$

Comments: Table 1 shows the positions and allelic frequencies of SNPs in the genes tested. These genes code for proteins involved in the recruitment and/or activation of basophils and Th1 lymphocytes, cells which participate in resistance to ticks in experimental animals. ${ }^{7}$ Some SNPs were located in coding regions, but resulted in silent substitutions. Tables S2 \& S3 show complete data for the SNPs and the constructed haplotypes respectively. A single, statistically significant $(P=0.0323)$ deviation from Hardy-Weinberg equilibrium, which may be expected by chance, was observed for the IGF1 AF404761:g.1388C>T SNP in Nelore. The SNPs will be useful in association studies of composite/segregating populations resulting from crosses of $B$. taurus and $B$. indicus breeds to ascertain if these markers are associated with causal mutations that confer cattle with resistance to R. microplus.

Acknowledgements: This study was supported by $\mathrm{CNPq}$ and FAPESP.

\section{References}

1 Jensen K. et al. (2007) Parasitol Today 23, 439-44.

2 Ewing B. et al. (1998) Genome Res 8, 186-94.

3 Gordon D. et al. (1998) Genome Res 8, 195-202.

4 Peakall R. \& Smouse P. E. (2006) Mol Ecol Notes 6, 288-95.

5 Excoffier L. \& Slatkin M. (1995) Mol Biol Evol 12, 921-7.

6 Raymond M. \& Rousset F. (1995) J Hered 86, 248-9.

Table 1 Positions and allelic frequencies of SNPs in genes that code for molecules of the immune system and that have exhibited significant differences between tick-resistant (Nelore, Bos indicus) and tick-susceptible (Holstein, Bos taurus) breeds.

\begin{tabular}{|c|c|c|c|c|c|c|}
\hline \multirow[b]{2}{*}{ Gene } & \multirow{2}{*}{$\begin{array}{l}\text { dbSNP } \\
\text { accession no. }\end{array}$} & \multirow{2}{*}{$\begin{array}{l}\text { Sequence variant/ } \\
\text { SNP position }\end{array}$} & \multirow{2}{*}{$\begin{array}{l}\text { Minor } \\
\text { allele }\end{array}$} & \multicolumn{2}{|c|}{ Frequency of minor allele } & \multirow{2}{*}{$\begin{array}{l}P \text {-value } \\
\text { (Fisher's exact } \\
\text { test) }\end{array}$} \\
\hline & & & & Nelore & Holstein & \\
\hline CXCL10 & ss82716009 & NW_931725:g.1077G>A & A & 0.4667 & 0.0313 & 0.0001 \\
\hline \multirow[t]{2}{*}{$C C L 2$} & ss82716026 & L32659:g.2057G>A & $A$ & 0.3438 & 0.0000 & 0.0003 \\
\hline & ss82716046 & L32659:g.2420C>T & $\mathrm{T}$ & 0.4333 & 0.0000 & 0.0001 \\
\hline$C C L 3$ & ss82716097 & NW_929444:g.379T>C & C & 0.4667 & 0.0357 & 0.0002 \\
\hline IGF1 & ss82716076 & AF404761:g.1388C>T & $\mathrm{T}$ & 0.0625 & 0.3750 & 0.0052 \\
\hline \multirow[t]{2}{*}{$T N F$} & ss82716148 & AF011926:g.2439A>G & G & 0.5714 & 0.0000 & 0.0001 \\
\hline & ss82716154 & AF011926:g.2659G>A & A & 0.1071 & 0.4375 & 0.0086 \\
\hline \multirow[t]{4}{*}{ IFNG } & ss82716164 & Z54144:g.2781G>T & $\mathrm{T}$ & 0.5417 & 0.0333 & 0.0001 \\
\hline & ss82716176 & Z54144:g.2896G>T & $\mathrm{T}$ & 0.3125 & 0.0000 & 0.0009 \\
\hline & ss82716188 & Z54144:g.3024T>G & G & 0.5625 & 0.0000 & 0.0001 \\
\hline & ss82716193 & Z54144:g.3028T>G & G & 0.5313 & 0.0000 & 0.0001 \\
\hline
\end{tabular}


7 Ribeiro J. M. \& Francischetti I. M. (2003) Аnnu Rev Entomol 48, 73-88.

Correspondence: I. K. F. de Miranda Santos (imsantos@fmrp. usp.br)

\section{Supplementary material}

The following supplementary material is available for this article online from http://www.blackwell-synergy.com/doi/full/ 10.1111/j.1365-2052.2008.01713.x

Table S1 Primer sequences employed for amplifying candidate genes and corresponding annealing temperatures and sizes of PCR fragments.

Table S2 Positions and allelic frequencies of SNPs in genes coding for molecules of the immune system in tick-resistant (Nelore, Bos indicus) and tick-susceptible (Holstein, Bos taurus) breeds.

Table S3 Frequencies of haplotypes in genes coding for molecules of the immune system in tick-resistant (Nelore, Bos indicus) and tick-susceptible (Holstein, Bos taurus) breeds.

Please note: Blackwell Publishing is not responsible for the content or functionality of any supplementary materials supplied by the authors.

doi:10.1111/j.1365-2052.2008.01718.x

\section{Microsatellite flanking regions: a SNP mine in South African abalone (Haliotis midae)}

\section{Rhode, R. Slabbert and R. Roodt-Wilding}

Department of Genetics, University of Stellenbosch, Private Bag X1, Matieland 7602, South Africa

Accepted for publication 6 February 2008

Source/description: Haliotis midae is the only commercial abalone species in South Africa and is threatened by overexploitation. Thus aquaculture enterprises are depending on genetic management to increase production. SNP markers are gaining popularity for use in genetic analyses. Previous studies have revealed the polymorphic nature of the flanking regions of microsatellite markers. ${ }^{1,2}$ Investigated here is the viability of these sequences as a SNP source in H. midae.

SNP identification: Four microsatellite markers were selected based on flanking region size and low null allele frequency. ${ }^{3}$ Primers were designed to amplify microsatellites and flanking sequences (Appendix S1 and Table S1) in 45 animals that represented three sampling populations from the south, east and west coast of South Africa (15 each). PCR products were sequenced and aligned, and SNPs were identified by investigating sequence variation amongst individuals. Twelve novel SNPs were identified amongst the flanking regions of the four microsatellite loci investigated (Table S2).

SNP analysis: Allele frequencies and heterozygosities were calculated, and tests for Hardy-Weinberg equilibrium (HWE) were performed (Table S2). The 12 SNPs demonstrated a minor allele frequency $>0.05$ and an average heterozygosity of 0.2837 , qualifying these SNPs for use in genetic analyses. ${ }^{4}$ Six SNPs deviated from HWE, and SNP heterozygosities were lower compared to microsatellites. ${ }^{5}$ However, the SNP heterozygosities for H. midae correlated with SNP heterozygosities found for the scallop. ${ }^{6}$

SNP density was one for every $113 \mathrm{bp}$. This is higher than the estimated average genome-wide distribution of SNPs, ${ }^{7}$ indicating the viability of microsatellite flanking sequences as a future SNP source. The transition-to-transversion ratio, equal to one, is different than what was found for birds and mammals, which demonstrated higher ratios. ${ }^{4}$ This deviation from the expected is probably due to the lack of characterized SNPs in the H. midae genome. A ratio of 1.3 was recently found in the oyster (Crassostrea virginica). ${ }^{8}$

Comments: The development of molecular markers, especially SNPs, will be of significant value in genome characterization and population management of $H$. midae. Microsatellite flanking SNPs in particular can play an important role in resolving population structure and phylogeny, because utilising microsatellite/SNP haplotypes will increase resolving power by negating the effects of microsatellite size homoplasy. ${ }^{1}$ The domestication and conservation of the vulnerable yet economically important Haliotis midae will be fast-tracked by the implementation of genetic management practices that utilise molecular marker technology.

Acknowledgements: The authors would like to thank A. E. Bester for technical advice and assistance as well as the following institutions for biological materials and funding: Abagold (Pty) Ltd, Aquafarm (Pty) Ltd, HIK Abalone Farm (Pty) Ltd, Irvin and Johnson Ltd, Innovation Fund, National Research Foundation and Roman Bay Sea Farm (Pty) Ltd.

\section{References}

1 Blankenship S. M. et al. (2002) Mol Biol Evol 19, 1943-51.

2 Ablett G. et al. (2006) Mol Breed 17, 281-9.

3 Slabbert R. et al. (2008) J World Aquacult Soc (In press).

4 Vignal A. et al. (2002) Genet Sel Evol 34, 275-305.

5 Evans B. et al. (2004) Aquaculture 233, 109-27.

6 Elfstorm C. M. et al. (2005) Mol Ecol Notes 5, 406-9.

7 Rengmark A. H. et al. (2006) Aquaculture 253, 229-37.

8 Quilang J. et al. (2007) BMC Genomics 8, 157-67.

Correspondence: R. Roodt-Wilding (roodt@sun.ac.za)

\section{Supplementary material}

The following supplementary material is available for this article online from http://www.blackwell-synergy.com/doi/full/ 10.1111/j.1365-2052.2008.01718.x

Appendix S1 Polymerase chain reaction conditions.

Table S1 Microsatellite locus and primer information used for the PCR amplification and sequencing of the microsatellite flanking regions.

Table S2 Allele frequencies, heterozygosities and tests for Hardy-Weinberg equilibrium (HWE) for microsatellites investigated in the study.

Please note: Blackwell Publishing is not responsible for the content or functionality of any supplementary materials supplied by the authors. 